\title{
A combinação entre estratégias deliberadas e emergentes em organizações: estudo de casos comparativos em ambientes dinâmicos
}

\author{
Rudolf Gabrich \\ Mestre em Administração (FDC/PUC Minas) - Cursa o \\ Doutorado no Instituto de Empresa (Madri - Espanha) \\ Professor da Fundação Dom Cabral \\ rudolf@fdc.org.br
}

\section{José Márcio de Castro}

Doutor em Administração pela Faculdade de Economia

e Administração da Universidade de São Paulo/FEA/

USP

Professor do Programa de pós-graduação em

Administração(PPGA) da Pontifícia Universidade

Católica de Minas Gerais

josemarcio@pucminas.br
Contextus

ISSNe 2178-9258 (ISSN 1678-2089)

Organização: Comitê Científico Interinstitucional Editor Científico: Marcelle Colares Oliveira Avaliação: Double Blind Review pelo SEER/OJS Revisão: Gramatical, normativa e de formatação Recebimento: 04/04/2011 Aprovação: 30/07/2013

\section{RESUMO:}

O objetivo deste artigo é examinar a dinâmica do surgimento de estratégias emergentes em organizações que fazem uso de processos deliberados de formulação estratégica. Especificamente, o objetivo é analisar como e por que ocorre nas organizações estudadas a combinação de emersão e de deliberação estratégica. Para isso, desenvolveu-se um estudo de casos comparativos em duas organizações situadas em ambientes dinâmicos. Os resultados indicam que as organizações combinam estratégias deliberadas e estratégias emergentes para aproveitar as oportunidades ou acomodar as pressões oriundas do ambiente externo. Além disso, há evidências de que o espaço para o surgimento de estratégias emergentes bem como sua combinação com estratégias deliberadas seja influenciado pela natureza da estratégia deliberada e dos fatores da arquitetura organizacional - estrutura, coordenação, sistemas de controle gerencial e de incentivos. Em outros termos, significa que quanto mais restrito o escopo da estratégia deliberada e quanto mais rígido os fatores da arquitetura organizacional maior o grau de dificuldade para a emersão e a consolidação dessas estratégias emergentes. Por fim, os resultados sugerem que o manejo da capacidade lateral da organização parece influenciar as estratégias emergentes.

Palavras-chave: Estratégia deliberada. Estratégia emergente. Formulação estratégica. Arquitetura organizacional. Ambiente dinâmico.

\section{ABSTRACT:}

This article discusses the dynamics of emergent strategies in companies using deliberate processes for strategic formulation. Specifically, we investigate how and why this process of combination occurs in the studied organizations, and how the organizational design - structure, lateral capability, control and reward systems interfere on the combination. For this purpose, we developed a multiple case study in two organizations theoretically operating in dynamic environments. The results indicate that organizations combine emergent and deliberate strategies either to take advantage of opportunities in the environment or to accommodate external pressures. Moreover, it seems that the process of emerging strategies and its combination with deliberated strategies is influenced by the nature of the intended strategy. It means, in other words, that the narrower the deliberated strategy scope, the more difficult is for an initiative to emerge and be consolidated as an emerging strategy. Finally, the results suggest that the use of lateral capability may influence emergent strategies.

Keywords: Deliberate strategies. Emergent strategies. Strategic formulation. Organizational architecture. Dynamic environments. 


\section{INTRODUÇÃO}

Com o objetivo de antecipar cenários e neutralizar a incerteza ambiental, as organizações, geralmente, recorrem a processos prescritivos de formulação estratégica (planejamento estratégico) para lidar com questões essenciais à sua sobrevivência (ELBANNA, 2006). Trata-se de uma crença subjacente de que a estratégia pode ser deliberada por meio de um processo formalizado e metódico de concepção, levando, consequentemente, a uma melhor adaptação da organização aos fatores dos ambientes externo e interno (MINTZBERG, 2004; OLIVEIRA et al., 2011).

Os processos prescritivos se preocupam em estabelecer a maneira pelas quais as estratégias devem ser formuladas (MINTZBERG; AHLSTRAND; LAMPEL, 2000), o que ocorre através de uma sequência de passos racionais analíticos (ANDERSEN, 2004). Além disso, são, em geral, caracterizados pela separação entre concepção e ação, ou seja, as estratégias são a priori criadas pela administração superior para em seguida serem desdobradas em planos detalhados e implementados pelos demais colaboradores (MARIOTTO, 2003; BOSSIDY; CHARAN, 2003).

Todavia, há na literatura diversas críticas relacionadas às limitações das estratégias deliberadas como, por exemplo, o fato de desconsiderar a aprendizagem (MINTZBERG, 1978), a tendência de extrapolar o passado para a construção de estratégias (BOSSIDY; CHARAN, 2003) e a dificuldade dos processos deliberados em lidar com ambientes de mudanças contínuas (MARIOTTO, 2003). Ademais, oportunidades de negócios são perdidas pela organização na medida em que a prescrição estratégica não incentiva ações de empreendedores autônomos, os quais poderiam mobilizar recursos corporativos para aproveitá-las. Essas oportunidades propiciariam uma melhor adaptação ao ambiente e proveriam matéria-prima para a renovação estratégica (BURGELMAN, 1983a).

Contrapondo-se aos processos prescritivos estão os processos descritivos, em que a formulação estratégica se estende a outros indivíduos, forças e agentes da organização, para além dos ocupantes de postos da administração superior. O resultado desse processo são as estratégias emergentes ou que emergem na organização em resposta a oportunidades do ambiente (MINTZBERG; AHLSTRAND; LAMPEL, 2000; MARIOTTO, 2003). Nesses modelos, o papel da administração superior é delimitar premissas estratégicas abrangentes o suficiente para estimular a inovação na linha de frente, assumindo o risco e nutrindo o desenvolvimento de ideias com maiores potenciais (ANDERSEN, 2004).

Entretanto, além de críticas aos processos descritivos, há na literatura suposições de que o processo racional ou deliberado produza resultados superiores aos gerados pelos processos intuitivos (ELBANNA, 2006), posto que, nas estratégias emergentes, os gerentes podem se tornar impacientes com rotinas ou detalhes e chegar a conclusões prematuras, ignorando fatores relevantes (SAUTER, 1999).

Dadas as críticas aos processos deliberados e emergentes, uma questão importante de pesquisa é o estudo da combinação desses processos como alternativa para o aproveitamento dos pontos fortes de cada um dos processos (BURGELMAN, 1983b; MINTZBERG; AHLSTRAND; LAMPEL, 2000; MARIOTTO, 2003; CALDEIRA et al., 2009; LAVARDA; CANET-GINER; PERIS-BONET, 2010). Além disso, a literatura tem apontado para a utilização de ambas as abordagens (CALDEIRA et al., 2009; OLIVEIRA et al., 2011), embora grande parte dos estudos brasileiros tenha, até então, concentrado esforços em processos deliberados (BIGNETTI; PAIVA, 2002). Esse dado reforça a necessidade de pesquisas adicionais dirigidas ao processo de emersão (MARIOTTO, 2003), isto é, a formulação de um modelo, detalhado e útil, de formação contínua de estratégia, e a maneira de superpor o planejamento estratégico à formação contínua de estratégias e vice-versa.

Nesse contexto, este artigo discute os resultados de uma pesquisa conduzida com o intuito de analisar e compreender o processo de reconhecimento e fomento de estratégias emergentes (emersão) e sua combinação com o planejamento estratégico formal (deliberação) na organização. Para isso, buscou-se na literatura suporte teórico sobre estratégias emergentes (LINDBLOM, 1959; MINTZBERG, 1978; QUINN, 1980; BURGELMAN, 1983a; ARAÚJO; EASTON, 1996; MARIOTTO, 2003; 
ANDERSEN, 2004; SILLINCE; JARZABKOWSKI; SHAW, 2012) e a combinação entre deliberação e emersão (BURGELMAN, 1983a; MINTZBERG; AHLSTRAND; LAMPEL, 2000; MARIOTTO, 2003; CALDEIRA et al., 2009; LAVARDA; CANET-GINER; PERIS-BONET, 2011; OLIVEIRA et al., 2011), para compreender como e por que as organizações combinam estratégias deliberadas e emergentes e que fatores interferem nesse processo.

No desenvolvimento da pesquisa, optou-se pelo estudo de caso de natureza qualitativa (EISENHARDT, 1989; YIN, 2005) e selecionaram-se, então, dois casos nos quais foi previamente identificado o fenômeno da emersão de estratégia ancorada em modelos deliberados de formulação estratégica.

Um primeiro resultado indica que as organizações combinam estratégias emergentes e deliberadas para aproveitar oportunidades ou acomodar pressões oriundas do ambiente externo. Outro resultado sugere que o espaço para o surgimento de estratégias emergentes bem como sua combinação com estratégias deliberadas é influenciado pelo escopo da estratégia deliberada e por fatores da arquitetura organizacional. Por fim, o aumento da capacidade lateral da organização, ou seja, a habilidade de construção e a gestão de mecanismos de coordenação horizontal parecem colaborar com a consolidação de estratégias emergentes.

Uma primeira contribuição do estudo foi entender a dinâmica do surgimento das estratégias emergentes e como elas são tratadas e incorporadas (ou não) à estratégia formal da organização. Uma segunda contribuição diz respeito à compreensão de como os fatores da arquitetura organizacional - estrutura, coordenação, sistemas de controle gerencial e de incentivos - contribuem tanto para o aparecimento das estratégias emergentes como para a sua consolidação nas organizações. Por fim, outra contribuição foi a compreensão dos efeitos do ambiente externo e das oportunidades internas para a emersão de estratégias.

Para além desta introdução, este artigo está dividido em quatro partes. Na primeira parte, é feita uma revisão crítica da literatura abordando os estudos sobre estratégias deliberadas e estratégias emergentes. Em seguida, faz-se uma discussão teórica sobre a combinação entre deliberação e emersão e a relação com os fatores da arquitetura organizacional. A terceira parte contém os procedimentos metodológicos, e na quarta parte apresentam-se e analisam-se os dados e os resultados encontrados. Finalmente, a última parte do artigo contém as principais conclusões e contribuições do presente trabalho, bem como sugestões para novas investigações empíricas.

\section{REFERENCIAL TEÓRICO}

\subsection{Processos Deliberados e Emergentes de Estratégia}

Ao sistematizarem as escolas de processos de formulação estratégica, Mintzberg, Ahlstrand e Lampel (2000) tipificaram as três primeiras escolas - design, planejamento e posicionamento - como processos de natureza prescritiva e deliberada, enquanto as outras seis escolas - empreendedora, cognitiva, da aprendizagem, do poder, cultural e ambiental - foram classificadas como escolas de natureza descritiva. A última, a escola de configuração, agrupa vários elementos do processo e do conteúdo de formulação estratégica em diferentes estágios do ciclo de vida das organizações.

Especificamente em relação ao primeiro grupo, o processo deliberado de formulação estratégica pode ser dividido em quatro etapas: i) formulação; ii) implementação; iii) controle de resultados e ajuste de sistemas; iv) retroalimentação (MAYO; BROWN, 1999). Além disso, a estratégia pode ser configurada mediante uma sequência de passos racionais, incluindo a definição do objetivo ou missão, a análise da concorrência, a verificação dos procedimentos internos, o controle estratégico, entre outros (ANDERSEN, 2004).

Em relação à formulação, Andrews (1980) sugere que toda organização deve ter um conjunto de fins ou metas que a conduza em direção a um objetivo deliberadamente escolhido. Assim, os fins e as metas devem ser definidos a partir da análise de forças e fraquezas da organização vis$\grave{a}$-vis as oportunidades e ameaças existentes no ambiente. Essa estrutura, que ficou conhecida como SWOT (Strengths, Weaknesses, Opportunities, Threats), tornou- 
se sinônimo de racionalidade de ação planejada. A partir de então, vários autores se esforçaram para sofisticar a matriz SWOT, procurando dividir o modelo em etapas claramente delimitadas e representadas em complexos fluxogramas de perguntas e respostas com vistas ao desenvolvimento dos objetivos e ao auxílio na formulação da estratégia (GILMORE; BRANDENBURG, 1962; STEINER, 1969; LORANGE; VANCIL, 1977; STEINER, 1979; HAX; MAILUF, 1991; RIGBY, 1993; DYSON, 2004; AMIN; RAZMI; ZHANG, 2011).

Por outro lado, a implementação estratégica materializa o desenvolvimento de longo prazo de uma organização pela articulação de planos de negócios detalhados, com horizonte de tempo para o alcance dos marcos e como uma primeira estimativa dos recursos estratégicos requeridos (HAX; MAILUF, 1991). A partir daí são estabelecidas as metas de acompanhamento dos compromissos e, uma vez não atingidas, são objeto de medidas corretivas. Por fim, o processo se encerra com a retroalimentação, que subsidiará o próximo ciclo estratégico (BOSSIDY; CHARAN, 2003).

Embora alguns autores tenham encontrado um relacionamento positivo entre a utilização de processos deliberados de formulação estratégica e a melhoria no desempenho organizacional (THUNE; HOUSE, 1970; KARGER; MALIK, 1975; ANDERSEN, 2004), outros, no entanto, não encontraram qualquer consistência nessa relação de causa e efeito (LEONTIADES; TENZEL, 1980; SAPP; SEILER, 1981; ROBINSON; PEARCE, 1983; PEARCE; ROBBINS; ROBINSON, 1987; HAMBRICK; CANNELLA, 1989; KUKALIS, 1991; HUNGER; WHEELEN, 2002).

Há, ainda, na literatura, um conjunto de críticas às limitações do processo deliberado de formulação estratégica. Mintzberg (1978), por exemplo, assinala que a dicotomia entre formulação e implementação estratégica é falsa, posto que ignora o papel do aprendizado na concepção da estratégia intencionada. Além disso, Mintzberg (2004) dedicou uma extensa crítica ao processo deliberado, especialmente no tocante aos resultados, considerados pífios, pelo autor. Por outro lado, Bossidy e Charan (2003) argumentam que a estratégia deliberada não deve ser uma compilação de indicadores extrapolados ano após ano, mas, pelo contrário, deve originar-se da mente das pessoas que estão mais próximas da ação e que entendem seus mercados, seus recursos e pontos fortes e fracos. Na mesma perspectiva, outros estudos sustentam que a maneira tradicional de desenvolver a estratégia, em um processo periódico e formal de planejamento, já não é mais suficiente para o enfrentamento das contínuas e complexas modificações no ambiente de negócios (MARIOTTO, 2003), fazendo-se necessária uma combinação de abordagens (ANDERSEN, 2004; LAVARDA; CANET-GINER; PERIS-BONET, 2011; OLIVEIRA et al., 2011).

Como contraponto às críticas e às limitações do processo deliberado de estratégia, a perspectiva conhecida como estratégia emergente vem ganhando espaço. Um dos primeiros autores a reconhecer a necessidade de uma filosofia de formulação estratégica diferente do tradicional planejamento estratégico foi Lindblom (1959). O autor argumenta que o principal recurso do gestor é a sua própria experiência e que a formulação, por exemplo, de políticas públicas, ocorre em um processo serial e fragmentado, ao longo do tempo, a partir de uma sucessão de várias decisões individuais que se conectam em um conjunto maior. Lindblom (1959) cunhou esse padrão de comportamento de "comparações sucessivas limitadas".

Posteriormente, Quinn (1980), partindo da perspectiva de Lindblom (1959), concluiu que as mudanças significativas nas estratégias das organizações raramente se originavam do sistema racional-analítico tão comum na literatura sobre estratégia, mas, ao contrário, derivavam de um processo fragmentado, evolucionário e bastante intuitivo. Nesses termos, o autor sugere que, em situações de eventos externos ou internos inesperados, os gestores deveriam fazer uso do que ele denominou de "incrementalismo lógico". Nesse modelo, as decisões internas fluem em conjunto com eventos externos, mas guiadas de forma proativa na direção de estratégias conscientes. Assim, administrar estrategicamente significa desenvolver ou manter nas mentes dos executivos um padrão consistente entre as decisões tomadas (QUINN, 1980). 
Entretanto, o termo "estratégia emergente" só vai ser introduzido nos anos de 1970 por Mintzberg (1978), quando o autor tipificou dois tipos de estratégias, as intencionadas e as realizadas, que podiam ser combinadas de três maneiras: i) estratégias intencionadas que são realizadas; ii) estratégias intencionadas que não são realizadas; iii) estratégias realizadas que nunca foram intencionadas (estratégias emergentes). Nesta última, a estratégia não é apenas um plano a ser rigidamente implementado, mas um padrão que se forma a partir de um conjunto, de uma sequência de decisões e ações, tornando-se uma estratégia emergente (MINTZBERG, 1978).

A estratégia emerge, portanto, a partir de um processo até certo ponto ao acaso, em resposta a algum fenômeno do ambiente (BURGELMAN, 1983a; ANDERSEN, 2004; LAVARDA; CANET-GINER; PERIS-BONET, 2011; OLIVEIRA et al., 2011). Resulta de autorizações finais da administração superior a projetos que absorvem com sucesso os recursos excedentes da organização e prometem fazê-lo de maneira lucrativa no futuro. Entretanto, Araújo e Easton (1996) argumentam que essa consistência (padrão) de decisões pode originar-se tanto de fontes internas - tais como processos cognitivos, padrões de discurso, práticas culturais e processos políticos - como também de fontes externas, tais como a natureza dos relacionamentos de troca com os quais a organização se envolve, os relacionamentos de trocas institucionais e as estruturas de rede. Além disso, a estratégia não é imposta pela administração superior, podendo emergir como consequência do trabalho em grupo, ou seja, decorrente de um processo descentralizado (ANDERSEN, 2004; LAVARDA; CANET-GINER; PERIS-BONET, 2010; 2011).

Todavia, há também na literatura diversas críticas às limitações da perspectiva de emersão estratégica. Por exemplo, organizações baseadas exclusivamente em estratégias emergentes podem terminar sem qualquer estratégia, tanto em razão da inovação fragmentada quanto pelo excesso de ênfase na aprendizagem (JOHNSON, 1987; HAYES; JAIKUMAR, 1988). Mintzberg, Ahlstrand e Lampel (2000) também argumentam que há situações em que não se pode confiar somente em estratégias emergentes, tal como em épocas de crise, quando a organização pode necessitar de um líder vigoroso que já tenha uma visão estratégica de como recuperá-la. Entretanto, mesmo em condições estáveis, algumas organizações se beneficiariam de visões estratégicas originadas mais em um empreendedorismo centralizado do que na aprendizagem descentralizada. Por fim, organizações que privilegiam estratégias emergentes podem-se ver perseguindo uma estratégia errada, já que o aprendizado incremental pode estimular o surgimento de estratégias que ninguém nunca quis ou pretendeu implementar (MINTZBERG; AHLSTRAND; LAMPEL, 2000; MARIOTTO, 2003).

Uma vez que poucas estratégias podem ser consideradas puramente deliberadas ou puramente emergentes (MINTZBERG, 2004), pois implicariam aprendizagem zero ou controle zero, ou seja, na medida em que " $[\ldots]$ todo comportamento estratégico real deveria combinar controle deliberado com aprendizado emergente" (MINTZBERG; AHLSTRAND; LAMPEL, 2000, p. 147), a perspectiva da combinação entre deliberação e emersão parece ganhar força tanto na pesquisa acadêmica como na prática das organizações.

\subsection{Combinando Estratégias Deliberadas e Emergentes}

Existem na literatura sobre estratégia diversas pesquisas que sugerem o relacionamento entre deliberação e emersão (ANDERSEN, 2004; LAVARDA; CANETGINER; PERIS-BONET, 2010; 2011), bem como os condicionantes que afetam a eficácia da combinação e, principalmente, da incorporação da emersão na organização. Esses condicionantes incluem, por exemplo, estratégias intencionadas que, na medida em que são colocadas em prática, mudam sua forma e tornam-se, em parte, emergentes; estratégias emergentes que vêm sendo desenvolvidas perifericamente na organização e terminam por ser formalizadas como estratégias deliberadas; estratégias deliberadas que são implementadas muito além de suas intenções originais (MINTZBERG, 1978).

Alguns estudos sugerem um modelo envolvendo interações dinâmicas entre o comportamento estratégico, 
os processos corporativos e o conceito de estratégia utilizado pelas organizações (BURGELMAN, 1983a; ANDERSEN, 2004; CALDEIRA et al., 2009; ELBANNA, 2006; LAVARDA; CANET-GINER; PERISBONET, 2010; 2011; OLIVEIRA et al., 2011). Nesse modelo, o conceito de estratégia corporativa representa a estratégia explícita definida com base nos sucessos e fracassos do passado. Essa estratégia corporativa induz um comportamento estratégico concernente com as categorias atuais utilizadas no planejamento estratégico da organização e relacionadas com o ambiente externo atual; ao mesmo tempo, essa estratégia induz ainda um contexto estrutural, composto por fatores que buscam manter o comportamento estratégico nos níveis operacionais alinhados com o conceito de estratégia corrente (BURGELMAN, 1983a).

Todavia, os indivíduos também geram certa quantidade de comportamento estratégico autônomo que não se encaixa nas categorias atuais do planejamento estratégico da organização. Por meio desses comportamentos, novos segmentos ambientais são instituídos e, consequentemente, o ambiente da organização é redefinido. Em tal perspectiva, o comportamento estratégico autônomo provê a matéria-prima para a renovação estratégica, mas esse comportamento precisa ser aceito pela organização e integrado ao atual conceito de estratégia vigente (BURGELMAN, 1983a). Essa tarefa é realizada pelo contexto estratégico, ou seja, pelos mecanismos por meio dos quais a gerência média questiona o conceito atual de estratégia e fornece à direção superior a oportunidade de abarcar, retroativamente, o comportamento estratégico autônomo (BURGELMAN, 1983a). Dessa forma, a gerência média pode ser dirigente da estratégia organizacional atuando como base para a renovação estratégica em um processo bottom-up (MANTERE, 2008; LAVARDA; CANET-GINER; PERIS-BONET, 2010).

No modelo sugerido por Mintzberg, Ahlstrand e Lampel (2000), as estratégias inicialmente crescem como ervas daninhas em um jardim, lançando raízes em todos os tipos de lugar, já que praticamente em toda parte da organização as pessoas têm a capacidade de aprender e empreender. Essas estratégias, como apontam Lavarda, Canet-Giner e Peris-Bonet (2010), tornam-se organizacionais quando os padrões proliferam e permeiam o comportamento da organização, transformando-se em coletivas.

Mariotto (2003), por sua vez, propõe uma estrutura conceitual que combina dois subprocessos que evoluem paralelamente na organização. De um lado, os objetivos gerais e a visão da organização norteiam a formulação de estratégias intencionadas que, por seu turno, são transformadas em ações planejadas por meio de um processo deliberado de planejamento estratégico típico. Por outro lado, no processo intitulado como "formação contínua de estratégia", os atores da organização interagem no dia a dia com clientes e outros agentes, detectam novas oportunidades, identificam seus riscos e agem por iniciativa própria, mas sempre orientados pelos objetivos gerais e pela visão estabelecidos pela direção superior. Essas iniciativas são, então, transformadas em estratégias emergentes ao ser percebidas como padrões de comportamento eficientes. Essa combinação entre as duas abordagens estratégicas pode propiciar um elevado desempenho organizacional (CALDEIRA et al., 2009; LAVARDA; CANET-GINER; PERIS-BONET, 2011; OLIVEIRA et al., 2011).

A contribuição essencial dos gerentes para as estratégias emergentes está precisamente na manipulação dos fatores da arquitetura organizacional (GALBRAITH, 2002) ou contexto estrutural (BURGELMAN, 1983a) dentro do qual a geração dessas iniciativas toma forma. Ou seja, é essencial entender fatores como estrutura, coordenação e processos, controle gerencial e sistemas de incentivos que afetam o surgimento e a consolidação de estratégias emergentes na organização (MARIOTTO, 2003; ANDERSEN, 2004; LAVARDA; CANET-GINER; PERIS-BONET, 2010).

\subsection{Fatores da arquitetura organizacional}

Se a estrutura segue a estratégia (CHANDLER, 1998), definida esta última, a estrutura abre espaço para que outras decisões organizacionais tomem forma. Estruturas organizacionais podem ser mais rígidas ou mais flexíveis. Estruturas mais rígidas são caracterizadas por muitos níveis hierárquicos, processos mais regulados por meio de sistemas de controle e planejamento, especialização 
de tarefas e elevado grau de formalização e padronização, baixa integração e baixos níveis de participação e delegação (BURNS; STALKER, 1961; WOODWARD, 1965; HAGE, 1965; DONALDSON, 1985).

Nesse tipo de estrutura, estratégias emergentes podem encontrar maiores dificuldades para surgir, uma vez que somente mudanças incrementais de baixa importância seriam possíveis em uma estrutura formalizada e centralizada (MINTZBERG, 2004; MINTZBERG; QUINN; GHOSHAL, 2006). Por outro lado, em estruturas mais flexíveis, caracterizadas por menos rigidez na definição de papéis organizacionais e mais permeável à inovação e à adaptação (BURNS; STALKER, 1961; WOODWARD, 1965; HAGE, 1965; DONALDSON, 1985), a emersão de estratégias pode encontrar um terreno mais adequado (MINTZBERG, 2004).

No que concerne à coordenação, o ambiente atual das organizações impõe desafios que geralmente não encontram a melhor resposta em estruturas funcionais tradicionais (GALBRAITH, 2002). Nesses termos, o incremento da capacidade lateral da organização (GALBRAITH; DOWNEY; KATES, 2002) por meio da coordenação de questões não encaminhadas pela estrutura organizacional pode ser obtido pela criação de redes, fomentadas pela proximidade física, pelas comunidades de prática, e pelos encontros anuais, programas de treinamento e projetos especiais. Além disso, esse incremento da capacidade lateral pode derivar, também, do redesenho dos processos da organização e, também, do uso de times e papéis formais para a promoção da integração (GALBRAITH 2002).

Além disso, a integração horizontal dá aos colaboradores considerável liberdade, desde que respeitados certos limites - como os valores centrais da organização e a entrega de resultados com base em contratos de desempenho. Essa combinação de empowerment e suporte fortalecem o senso de autonomia e o espírito empreendedor, abrindo espaço às iniciativas emergentes e criando um círculo virtuoso (GHOSHAL; GRATTON, 2002).

O processo de controle - outro fator da arquitetura utilizado por gerentes nas organizações consiste de pelo menos quatro elementos: sensores, assessores, atuadores e sistemas de comunicação (ANTHONY; GOVINDARAJAN, 2000; RAPS, 2004; HREBINIAK, 2005). Os primeiros reportam o que está acontecendo na organização. Os assessores comparam as informações oriundas dos sensores com aquilo que é desejado. Os atuadores, em caso de desvio entre o desejado e o ocorrido, tomam as ações corretivas. Os sistemas de comunicação dizem aos gestores o que está acontecendo e como comparar com o desejado. Dessa forma, o processo deverá prover informações sobre a implementação de iniciativas estratégicas em relação aos resultados e aos tempos desejados, facilitando o aprendizado e a adaptação organizacional, na medida em que os gerentes tentam entender o problema e as razões lógicas que o sustentam (ANTHONY; GOVINDARAJAN, 2000; RAPS, 2004; HREBINIAK, 2005).

Todavia, o controle não requer, necessariamente, que todas as ações correspondam a planos determinados, uma vez que esses planos foram baseados em determinadas circunstâncias. Se as circunstâncias mudaram no momento da implementação ou se o gestor descobre uma melhor abordagem (estratégia emergente), o sistema de controle não deveria obstruir sua implementação. Em outras palavras, a conformidade não é necessariamente boa, assim como a não conformidade não é necessariamente ruim (ANTHONY; GOVINDARAJAN, 2000). Entretanto, Mintzberg (2004) critica a premissa básica de um sistema de controle assentado em uma hierarquia de objetivos e orçamentos com vistas a obter um determinado desempenho em relação ao qual os resultados podem ser mensurados. Para o autor, as organizações devem evitar injetar muita formalidade no sistema levando-o a perder a flexibilidade, a folga e a simplicidade, impedindo a criatividade e, por consequência, iniciativas emergentes.

Por fim, o sistema de incentivos, como um mecanismo que encoraja e motiva os gerentes a perseguir os objetivos organizacionais, bem como a monitorar o progresso da implementação (GALBRAITH, 2002), é, geralmente, atrelado ao alcance de metas utilizadas no sistema de controle da organização (STONICH, 1981; ANTHONY; GOVINDARAJAN, 2000). Os planos de incentivo podem ser de curto e longo prazos. Os incentivos de curto prazo 
baseiam-se no desempenho do ano corrente, enquanto os de longo prazo vinculam a compensação às realizações futuras (ANTHONY; GOVINDARAJAN, 2000).

Os incentivos devem ser positivos, diversificados e de duas naturezas: utilitários e psicológicos. Os primeiros têm valor extrínseco (salários, bônus e promoções), enquanto os últimos são intrínsecos (autonomia, trabalho agradável, identificação com o trabalho ou com os resultados) (HREBINIAK, 2005).

Ademais, incentivos adequados estão conectados a objetivos estratégicos, são mensuráveis, facilitam a contabilidade e nunca refletem distinções binárias do tipo "tudo ou nada". Por outro lado, a configuração dos sistemas de incentivo deve ser flexível e inteligente, incentivando a exploração de uma safra de estratégias ou, encorajando, quando necessário, a geração de novas iniciativas estratégicas (MINTZBERG, AHLSTRAND; LAMPEL, 2000). Assim, o papel da administração é o de "[...] saber quando resistir a mudanças em nome da eficiência e quando promovê-las em nome da adaptação externa" (MINTZBERG; AHLSTRAND; LAMPEL, 2000, p. 148).

O Quadro 1 sintetiza as categorias e os atributos derivados do referencial teórico, bem como as referências utilizadas.

\section{Quadro1 - Síntese teórica do contexto estrutural}

\begin{tabular}{|c|c|c|}
\hline Categoria & Atributos & Autores \\
\hline $\begin{array}{l}\text { Estratégia } \\
\text { Emergente }\end{array}$ & Estratégia horizontal & $\begin{array}{l}\text { MINTZBERG, } \\
\text { 1978; ARAÚJO; } \\
\text { EASTON, 1996; } \\
\text { ANDERSEN, } \\
\text { 2004; SILLINCE; } \\
\text { JARZABKOWSK } \\
\text { I; SHAW, 2012; } \\
\text { LAVARDA; } \\
\text { CANET-GINER; } \\
\text { PERIS-BONET; } \\
\text { 2010; 2011; }\end{array}$ \\
\hline $\begin{array}{l}\text { Estratégia } \\
\text { Deliberada }\end{array}$ & $\begin{array}{l}\text { Estratégia formal, metódica e } \\
\text { vertical }\end{array}$ & $\begin{array}{l}\text { MINTZBERG; } \\
\text { 1978; 2004; } \\
\text { MAILUF, 1991; } \\
\text { RIGBY, 1993; } \\
\text { MINTZBERG; } \\
\text { AHLSTRAND; } \\
\text { LAMPEL, 2000; } \\
\text { MARIOTTO; } \\
\text { 2003; HAX; } \\
\text { DYSON, 2004; } \\
\text { AMIN; RAZMI; } \\
\text { ZHANG, 2011 } \\
\end{array}$ \\
\hline
\end{tabular}

\begin{tabular}{|c|c|c|c|}
\hline $\begin{array}{l}\text { Combinação } \\
\text { de Estratégia }\end{array}$ & \multicolumn{2}{|c|}{$\begin{array}{l}\text { Combinação de ambas as } \\
\text { abordagens, deliberação e emersão }\end{array}$} & $\begin{array}{l}\text { MINTZBERG, } \\
\text { 1978; } \\
\text { BURGELMAN, } \\
\text { 1983A; } \\
\text { ANDERSEN, } \\
\text { 2004; } \\
\text { LAVARDA; } \\
\text { CANET-GINER; } \\
\text { PERIS-BONET, } \\
\text { 2011; OLIVEIRA } \\
\text { et al., 2011 }\end{array}$ \\
\hline \multirow{4}{*}{$\begin{array}{l}\text { Fatores da } \\
\text { arquitetura } \\
\text { organizacional } \\
\text { (contexto } \\
\text { estrutural) }\end{array}$} & Estrutura & $\begin{array}{l}\text { Estruturas } \\
\text { organizacionais } \\
\text { podem ser mais } \\
\text { rígidas ou mais } \\
\text { flexíveis. Afetam a } \\
\text { emersão de } \\
\text { estratégias }\end{array}$ & \begin{tabular}{|l} 
BURNS; \\
STALKER, 1961; \\
WOODWARD, \\
1965; HAGE, \\
$1965 ;$ \\
DONALDSON, \\
1985 \\
MINTZBERG, \\
2004; \\
MINTZBERG; \\
QUINN; \\
GHOSHAL, 2006
\end{tabular} \\
\hline & $\begin{array}{l}\text { Coordenação } \\
\text { e Processo }\end{array}$ & \begin{tabular}{|l|} 
A capacidade \\
lateral da \\
organização pode \\
ser incrementada \\
pela criação de \\
redes e redesenho de \\
processos e do uso \\
de times e papéis \\
formais. Abre \\
espaço para \\
iniciativas \\
emergentes \\
\end{tabular} & $\begin{array}{l}\text { GALBRAITH; } \\
\text { DOWNEY; } \\
\text { KATES, 2002; } \\
\text { GALBRAITH; } \\
2002\end{array}$ \\
\hline & $\begin{array}{l}\text { Controle } \\
\text { Gerencial }\end{array}$ & $\begin{array}{l}\text { Relevante para a } \\
\text { implementação de } \\
\text { iniciativas } \\
\text { estratégicas em } \\
\text { relação a resultados } \\
\text { e tempos desejados }\end{array}$ & $\begin{array}{l}\text { ANTHONY; } \\
\text { GOVINDARAJA } \\
\text { N, 2000; RAPS, } \\
2004 ; \\
\text { HREBINIAK, } \\
2005\end{array}$ \\
\hline & $\begin{array}{l}\text { Sistema de } \\
\text { incentivo }\end{array}$ & $\begin{array}{l}\text { Mecanismos que } \\
\text { encorajam e } \\
\text { motivam os gerentes } \\
\text { a perseguirem os } \\
\text { objetivos } \\
\text { organizacionais }\end{array}$ & $\begin{array}{l}\text { GALBRAITH, } \\
\text { 2002; STONICH, } \\
\text { 1981; } \\
\text { ANTHONY; } \\
\text { GOVINDARAJA } \\
\text { N, 2000; } \\
\text { HREBINIAK, } \\
2005\end{array}$ \\
\hline
\end{tabular}

Fonte: Elaborado pelos autores.

\section{METODOLOGIA DA PESQUISA}

Com o objetivo de investigar a dinâmica do surgimento de estratégias emergentes em organizações que fazem uso de processos deliberados de formulação estratégica, foi utilizado o método do estudo de caso (YIN, 2005) de natureza qualitativa (BONOMA, 1985; EISENHARDT, 1989). Entre as razões para a escolha do método do estudo de caso pode-se mencionar o contato direto do pesquisador com o fenômeno estudado por meio das pessoas nele envolvidas, o que permite entender não 
somente o que é óbvio, mas também o que está latente (MILLES; HUBERMAN, 1994). Essa proximidade é essencial para o objetivo de identificar e compreender, nas organizações, o que são as iniciativas emergentes. Além disso, o método do estudo de caso é a estratégia mais apropriada para descobrir e explorar novas áreas (combinação de estratégias deliberada e emergente em organizações), assim como desenvolver hipóteses (MILLES; HUBERMAN, 1994).

Em estudos de casos, a escolha dos objetos empíricos se baseia no interesse do caso em relação ao fenômeno em estudo e nas variáveis potencialmente relevantes. Casos não precisam e não devem ser randômicos (EISENHARDT, 1989), uma vez que o objetivo não é o da representatividade estatística, mas o da compreensão ampla e profunda do fenômeno. Sendo de natureza intencional, a seleção de casos adequados ao estudo foi norteada por dois critérios. No primeiro critério, buscou-se identificar organizações que utilizavam em suas atividades e em seus processos o planejamento estratégico formal, e, no segundo, procurou-se identificar organizações que apresentaram, recentemente, algum tipo de iniciativa emergente.

Para identificar a estratégia emergente e validar o caso como adequado ao estudo, comparou-se, longitudinalmente, ano a ano, o documento formal que representava a estratégia deliberada da organização. A estratégia emergente foi definida como aquela que surgiu espontaneamente de um período para outro, ou seja, aquela que, não tendo sido deliberada em determinado ano, aparece formalizada no ano seguinte. A partir desses critérios, foram identificadas quatro empresas em uma população de casos, entretanto apenas duas empresas permitiram o acesso para o estudo. Portanto, os dois casos foram selecionados porque faziam referência às estratégias emergentes, a saber: (i) o aparecimento de um novo serviço em empresas de contact center; (ii) iniciativas de diferenciação em uma empresa de papel e celulose.

Selecionados os casos, passou-se aos procedimentos de coleta de dados. Entre as várias fontes de evidências em um estudo de casos de natureza qualitativa
(EISENHARDT, 1989; YIN, 2005), priorizaram-se entrevistas em profundidade, documentos, arquivos e observação (YIN, 1981; GASKELL, 2003). A entrevista em profundidade é uma das técnicas mais importantes em estudos qualitativos (GASKELL, 2003). No entanto, considerando-se as dificuldades dos indivíduos em relembrarem fatos com exatidão, incorporaram-se à etapa de coleta de dados alguns procedimentos para reduzir erros em relatos retrospectivos (GOLDEN, 1992).

Primeiro, reconheceram-se as possíveis conexões emocionais dos respondentes com as estratégias às quais estiveram publicamente ligados e seus interesses mais amplos de retratarem um ponto de vista particular das organizações das quais são membros. Desse modo, procuraram-se evidências com base em múltiplos respondentes na organização, dando início ao processo de triangulação de dados (JICK, 1979). Posteriormente, cuidou-se dos incentivos inerentes a um programa de pesquisa, comprometendo-se com os entrevistados de que receberiam os resultados da investigação. Em seguida, foi dedicada especial atenção à datação de fatos passados, tomando-se os devidos cuidados com dados coletados após as mudanças organizacionais. Por fim, utilizou-se não somente de múltiplos respondentes, mas, também, de outras fontes de dados, como arquivos e documentos (especialmente os mapas estratégicos e o fluxo de macroprocessos das organizações), expandindose assim o processo de triangulação (JICK, 1979; EISENHARDT, 1989).

$\mathrm{Na}$ primeira parte da coleta de dados, realizaram-se entrevistas em profundidade baseadas em um conjunto de construtos identificados a partir do referencial teórico - processos deliberados de estratégia, processos emergentes e combinação de deliberação e emersão, bem como as variáveis da arquitetura organizacional (contexto estrutural) que influenciam no aparecimento e na consolidação das iniciativas estratégicas. Nesses termos, o roteiro de entrevista abordava questões (apenas um extrato) como: 1) Descreva a iniciativa que nasceu fora do processo formal de formulação estratégica e que ganhou em importância, terminando por ser formalizada; 2) Qual o papel da gerência de nível médio na promoção desse tipo de iniciativa estratégica na empresa? 3) 
Há algum tipo de processo interno formalizado para fomentar estratégias emergentes? 4) Como esse processo se relaciona com o planejamento estratégico formal? 5) Como era a estrutura da empresa (funcional, por produto ou serviço, por mercado, geográfica, por processo, ou uma combinação desses tipos)? 6) Qual o número de níveis hierárquicos? 7) Houve mudança em função da estratégia emergente?

A seleção dos respondentes obedeceu aos seguintes critérios: i) participação e envolvimento com a estratégia emergente; ii) participação e envolvimento com o planejamento estratégico formal; iii) envolvimento com o desenho da arquitetura organizacional - estrutura, processos, sistemas de controle e incentivo, entre outros elementos. As entrevistas duraram em média uma hora e trinta minutos cada uma. Foram realizadas cinco entrevistas no caso A e seis entrevistas no caso B, conforme detalhado no Quadro 2.

Quadro 2 - Entrevistas realizadas

\begin{tabular}{|c|c|c|}
\hline $\begin{array}{l}\text { Aspectos gerais } \\
\text { das entrevistas }\end{array}$ & Caso A & Caso B \\
\hline Número & 5 & 6 \\
\hline Período & \multicolumn{2}{|c|}{2007 e 2008} \\
\hline Duração média & \multicolumn{2}{|c|}{$1 \mathrm{~h} 30 \mathrm{~min}$} \\
\hline \multirow{6}{*}{$\begin{array}{l}\text { Entrevistados } \\
\text { (executivos) }\end{array}$} & Diretor de operações & Gerente comercial \\
\hline & $\begin{array}{l}\text { Diretor de cobrança e } \\
\text { recuperação de créditos }\end{array}$ & $\begin{array}{l}\text { Gerente de pesquisa } \\
\text { e tecnologia }\end{array}$ \\
\hline & $\begin{array}{l}\text { Gerente de gestão e } \\
\text { desenvolvimento de } \\
\text { produtos }\end{array}$ & $\begin{array}{l}\text { Gerente de } \\
\text { planejamento } \\
\text { estratégico }\end{array}$ \\
\hline & Gerente de comunicação & Gerente industrial \\
\hline & Gerente de recursos humanos & $\begin{array}{l}\text { Coordenador de } \\
\text { recursos humanos }\end{array}$ \\
\hline & & $\begin{array}{l}\text { Coordenador de gestão } \\
\text { por processos }\end{array}$ \\
\hline
\end{tabular}

Fonte: Elaborado pelos autores.

Realizadas as entrevistas, passou-se à coleta de documentos e arquivos que pudessem complementar os dados da pesquisa. Utilizaram-se dados de demonstrações financeiras, relatório de administração, diagrama de macroprocessos, entre outros documentos, conforme pode ser visto no quadro 3 .
Quadro 3 - Relação de documentos e arquivos

\begin{tabular}{|c|l|l|}
\hline Ordem & \multicolumn{1}{|c|}{ Caso A } & \multicolumn{1}{c|}{ Caso B } \\
\hline 1 & $\begin{array}{l}\text { Demonstração financeira "pró- } \\
\text { forma"-31/12/ 2002 }\end{array}$ & $\begin{array}{l}\text { Mapa estratégico de } \\
28 / 02 / 2002\end{array}$ \\
\hline 2 & $\begin{array}{l}\text { Demonstração financeira "pró- } \\
\text { forma"-31/12/ 2003 }\end{array}$ & $\begin{array}{l}\text { Mapa estratégico de } \\
31 / 10 / 2003\end{array}$ \\
\hline 3 & $\begin{array}{l}\text { Relatório de administração - } \\
2004\end{array}$ & Relatório anual - 2002 \\
\hline 4 & Relatório anual - 2005 & Relatório anual -2003 \\
\hline 5 & Diagrama de macroprocessos & $\begin{array}{l}\text { Diagrama de } \\
\text { macroprocessos }\end{array}$ \\
\hline
\end{tabular}

Fonte: Elaborado pelos autores

A primeira atividade executada na análise dos dados foi a transcrição dos dados coletados nas entrevistas e nos documentos. Utilizando-se da análise de conteúdo (BARDIN, 1976), tomaram-se as categorias previamente estabelecidas a partir do referencial teórico e, após um processo de leitura e análise, as unidades de texto foram codificadas e classificadas nas categorias. Ao final do processo, tinha-se um corpus de análise referente ao caso A e outro referente ao caso B.

Posteriormente, como recomendado por Eisenhardt (1989), fez-se, primeiro, uma análise intracaso, de especial importância em estudos de caso, em razão do grande volume de dados, gerando-se, então, uma narrativa para o caso A, e, em seguida, uma narrativa para o caso B. A partir daí, realizou-se a análise cruzada de casos buscando alguns padrões entre os casos (EISENHARDT, 1989).

\section{DESCRIÇÃO E ANÁLISE DE DADOS}

\subsection{O Caso A}

\subsubsection{Deliberação e Emersão na Empresa de Contact Center}

A empresa iniciou as suas operações no final de 2000, como resposta de uma operadora de telecomunicações às oportunidades de terceirização de atividades de contact center que surgiram no Brasil. Até dezembro de 2004, a empresa esteve sob o controle de uma operadora de telecomunicações, quando, então, se tornou uma companhia independente. Em cinco anos de atividade, a empresa A foi a que obteve o maior crescimento em seu segmento no Brasil. A sua estratégia de negócios estava 
centrada no desenvolvimento de relacionamentos de longo prazo com grandes companhias consumidoras de serviços de relacionamento remoto com clientes.

O planejamento estratégico da empresa é realizado para um horizonte de três anos e revisto anualmente por um grupo composto pelo presidente e pelos diretores e gerentes, contando com o apoio de profissionais de suporte. Em um processo baseado em análises racionais, esse grupo dimensionava as demandas, definia as diretrizes estratégicas e planejava os investimentos. Com base nas diretrizes estratégicas, os gestores eram chamados a realizar a "contratação anual", elaborando posteriormente o orçamento de suas áreas com as metas de receitas, custos, investimentos e qualidade. Ao final desse processo, a equipe de gestão desdobrava as metas específicas para todos os gestores - da diretoria até os níveis de supervisão - alimentando dois sistemas: o Sistema de Informações Gerenciais (SIG) e o sistema de avaliação do desempenho, este último vinculado ao modelo de participação nos resultados.

O plano de negócios original da empresa previa que a sua atuação no mercado de contact center estivesse baseada em Serviços de Atendimento ao Cliente (SAC) e em serviços de televendas. Essa orientação estratégica guiou o contrato com o seu primeiro cliente ao final do ano 2000, uma operadora de telecomunicações, da qual assumiu os dois serviços. A partir daí, a estratégia adotada pela empresa foi de "[...] crescer no mercado com base nos serviços desenvolvidos em seu principal cliente" (Entrevista 1), no caso, a operadora de telecomunicações.

No ano de 2002, a orientação estratégica da empresa sofreu uma modificação resultante da iniciativa emergente de "Recuperação de Créditos", surgida no estado do Ceará, por iniciativa do então gerente regional. A partir das competências acumuladas em processos de clientes, o gerente regional percebeu que a atividade de cobrança e recuperação de créditos representava uma oportunidade de negócios que ainda não tinha sido vislumbrada pela empresa. O fato é que a inadimplência comprometia uma importante parte do faturamento da empresa de telecomunicações na região Nordeste, enquanto a atividade de cobrança estava sendo realizada por pequenas empresas locais com o emprego de procedimentos manuais e limitada tecnologia de gestão. A percepção pelo gerente dessa oportunidade levou-o a apresentar a proposta de assumir o serviço de cobrança ao superintendente regional da empresa de telecomunicações, tendo em vista o aproveitamento da capacidade ociosa dos equipamentos. Dessa iniciativa, surgiu a ideia de montar um projeto-piloto. A transferência da atividade de cobrança para a empresa de contact center foi realizada já no ano de 2002, marcando o início efetivo da operação derivada de uma iniciativa emergente.

A partir dessa operação com o primeiro cliente, a empresa percebeu que o serviço de "Recuperação de Créditos" apresentava uma importante característica de aprendizado que poderia subsidiar a expansão do negócio, isto é, entendeu que falar com quem decide é essencial para o sucesso do serviço de cobrança. Para isso, a empresa criou um cadastro vivo, baseado no Cadastro de Pessoas Físicas (CPF) e no Cadastro Nacional de Pessoas Jurídicas (CNPJ), incluindo dados tais como: i) quem é a pessoa que decide; ii) quando ela pode ser encontrada; iii) quais os meios de contato mais adequados, entre outros aspectos. Alimentado por esses dados, um discador automático gerenciava todas as ligações, aumentando assim a taxa de sucesso dos contatos. Além disso, os dados de CPF e CNPJ passaram a ser consultados sempre que uma nova carteira de cobrança era incorporada ao negócio, potencializando a produtividade e eficiência. Com isso, a empresa de contact center aumentou sua gama de clientes de "Recuperação de Créditos", expandindo seus serviços para empresas do setor financeiro, de telecomunicações, varejo, energia elétrica e de internet.

\subsubsection{A combinação de estratégias deliberadas e emergentes e o papel da arquitetura organizacional na empresa de contact center}

À medida que a empresa implantava o serviço de "Recuperação de Créditos" no restante do país, o seu controle foi centralizado na cidade do Rio de Janeiro. Concomitantemente, a empresa promoveu a alteração em sua estrutura passando de um modelo geográfico de distribuição de tarefas para um modelo híbrido geográfico/serviço, para finalmente, em agosto de 
2006, adotar uma estrutura por serviços com a criação de diretorias específicas para cada serviço prestado pela empresa, incluindo a "Recuperação de Créditos".

No início da operação da empresa, a coordenação era realizada por meio de reuniões mensais entre os diretores e os gerentes regionais. Essas reuniões tinham como propósito, por um lado, controlar o andamento das operações e, por outro, compartilhar práticas entre os gestores das diferentes regiões de operação da empresa. Em 2004, ainda sob a égide da estrutura híbrida geografia/ serviços, a empresa percebeu a necessidade de estimular a troca de melhores práticas e criou com esse propósito a "Gerência de Melhoria Contínua" que, entretanto, teve duração temporária. Após assumir em definitivo a configuração por serviços motivada pela estratégia emergente, foram criados mecanismos e funções para fomentar o compartilhamento de informações e práticas.

Um desses mecanismos ficou conhecido como CIRC e seu objetivo era centralizar a inteligência desenvolvida entre os vários clientes da empresa. Outro mecanismo criado foi a função de Gerente de Relacionamento, com a missão de ser o ponto de contato entre os clientes e a empresa, centralizando informações e trocando experiências com os outros gerentes. Outra função de compartilhamento era realizada pelo Grupo de Produtos, com foco nas futuras sinergias entre as diretorias da empresa. Além desses mecanismos e dessas funções, a empresa fez uso de outra prática para a coordenação horizontal, a partir da movimentação de pessoas. Os centros de excelência da empresa - unidades de desempenho reconhecidamente superiores - eram constantemente chamados a fornecer pessoal para outras operações, o que promoveu a disseminação de muitas práticas dentro da empresa.

Em razão das modificações na estrutura organizacional, motivadas pela emersão da estratégia, a empresa também estabeleceu alguns processos tanto no nível da gestão quanto no nível operacional. Em relação à gestão foram estabelecidos macroprocessos transversais em relação às diversas funções da empresa. Em termos operacionais, as atividades passaram a ter a rotina mais delimitada, tanto pela automatização quanto pelos discursos e pelas falas a serem utilizados pelos operadores.
O controle da gestão na empresa, no período analisado, era realizado com base no orçamento - peça-chave da gestão estratégica. Entretanto, esse procedimento permitia aos gestores liberdade de experimentação, desde que atendido o desempenho contratado com a empresa. No nível operacional, o controle do desempenho do operador foi modificado, passando a ser avaliado em relação aos créditos recuperados e não mais em razão dos contatos realizados.

A participação nos resultados era o sistema de incentivo utilizado pela empresa. Todavia, no início das operações, essa não era uma prática geral, mas tão somente uma ação pontual adotada por algumas áreas, em geral, relacionada com a tentativa de redução do absenteísmo. Com o tempo, esse sistema de incentivo foi sendo aprimorado e, ao final do período abarcado pela pesquisa, a participação nos resultados era uma prática geral, considerando aspectos individuais e coletivos, nos níveis gerenciais e operacionais. Do nível de coordenação para cima, manteve-se o padrão da empresa com metas alinhadas aos objetivos de curto prazo, tendo como base o orçamento aprovado. No nível operacional, entretanto, os critérios de participação de equipe de "Recuperação de Créditos" passaram a ser controlados por créditos recuperados e não mais por contato realizado.

Quadro 4 - Síntese das evidências do caso A

\begin{tabular}{|c|c|}
\hline Categorias & Evidências \\
\hline $\begin{array}{l}\text { Estratégia } \\
\text { Deliberada }\end{array}$ & $\begin{array}{l}\text { - A estratégia geral de desenvolvimento de mercado era: } \\
\text { "crescer no mercado com base nos serviços desenvolvidos em } \\
\text { seu principal cliente". } \\
\text { - O planejamento estratégico da empresa era realizado para um } \\
\text { horizonte de três anos e revisto anualmente por um grupo } \\
\text { composto pelo presidente e pelos diretores e gerentes. } \\
\text { - Os gestores realizavam a "contratação anual" e elaboravam o } \\
\text { orçamento de suas áreas com as metas de receitas, custos, } \\
\text { investimentos e qualidade. } \\
\text { - O plano de negócios previa que a sua atuação no mercado de } \\
\text { contact center estivesse baseada em Serviços de Atendimento } \\
\text { ao Cliente (SAC) e em serviços de televendas. }\end{array}$ \\
\hline & $\begin{array}{l}\text { - A identificação de oportunidade foi vislumbrada a partir das } \\
\text { competências acumuladas em processos de clientes. } \\
\text { - Por iniciativa de um gerente regional, a empresa modificou sua } \\
\text { estratégia passando a adotar a "recuperação de créditos". } \\
\text { - Montou-se um projeto-piloto. } \\
\text { - A transferência da atividade de cobrança foi realizada no ano } \\
\text { de } 2002 \text {. } \\
\text { - A empresa optou por assumir em definitivo a configuração por } \\
\text { serviços. }\end{array}$ \\
\hline $\begin{array}{c}\text { Combinação de } \\
\text { estratégias }\end{array}$ & $\begin{array}{l}\text { - Desenvolvimento de mercado (estratégia "guarda-chuva" com } \\
\text { desenvolvimento de produto/serviço, que emerge de } \\
\text { oportunidade interna). }\end{array}$ \\
\hline
\end{tabular}




\begin{tabular}{|c|c|}
\hline $\begin{array}{c}\text { Fatores da } \\
\text { arquitetura } \\
\text { organizacional }\end{array}$ & $\begin{array}{l}\text { - Centraliza seu controle na cidade do Rio de Janeiro. } \\
\text { - Passa de um modelo geográfico de distribuição de tarefas para } \\
\text { um modelo híbrido geográfico/serviço. } \\
\text { - Adota, em 2006, uma estrutura por serviços com a criação de } \\
\text { diretorias específicas para cada serviço prestado pela empresa, } \\
\text { incluindo a "Recuperação de Créditos". } \\
\text { - Cria mecanismos e funções para fomentar o compartilhamento } \\
\text { de informações e práticas, tais como CIRC e Gerente de } \\
\text { Relacionamento. } \\
\text { - A empresa estabelece processos tanto no nível da gestão } \\
\text { - nuanto no nível operacional. } \\
\text { transversais em relação às diversas funções da empresa. } \\
\text { - Em termos operacionais, as atividades passaram a ter a rotina } \\
\text { mais delimitada. } \\
\text { - Controla a gestão com base no orçamento, peça-chave da } \\
\text { gestão estratégica da empresa. } \\
\text { - Utiliza o sistema de incentivo de participação nos resultados. }\end{array}$ \\
\hline
\end{tabular}

Fonte: Dados da pesquisa

\subsection{O Caso B}

\subsubsection{Deliberação e Emersão na Empresa de Produção de Celulose}

A empresa é brasileira, líder mundial na produção de celulose, respondendo por cerca de $30 \%$ da oferta global do produto destinado à fabricação de papéis para impressão e redação, papéis sanitários e papéis especiais de elevado valor agregado. Suas operações florestais alcançam quatro estados do Brasil, com aproximadamente 263 mil hectares de plantios renováveis de eucalipto, intercalados com cerca de 140 mil hectares de reservas nativas, fundamentais para assegurar o equilíbrio do ecossistema. Sua capacidade nominal de produção, de três milhões de toneladas anuais de celulose, está distribuída por três unidades industriais.

O processo de formulação estratégica da empresa não era estruturado quando do surgimento da estratégia emergente. Para ela, a estratégia era mais o resultado da visão dos principais executivos do que de análises sistemáticas e racionais. Por um lado, a administração superior realizava continuamente uma revisão dos fundamentos do mapa estratégico e, eventualmente, redefinia os objetivos estratégicos que nele figuravam. Por outro lado, a revisão anual dos indicadores do mapa estratégico era formal e realizado pela diretoria e pelos gerentes. Tal revisão tinha por objetivo analisar o desempenho de curto prazo com base no mapa estratégico, revalidar os objetivos e desdobrá-los em indicadores gerenciais e operacionais. A partir daí, os gerentes da empresa se dedicavam a elaborar o planejamento operacional, cuja peça mais importante era o orçamento. Por fim, a execução da estratégia era acompanhada por meio de reuniões periódicas nas quais se comparava o que tinha sido realizado em relação ao previsto nos indicadores e no orçamento. Em casos de desvios, eram abertos relatórios de não conformidades que, necessariamente, davam origem a planos de ação.

O mapa estratégico da empresa, no período analisado, apresentava três estratégias genéricas, sendo a excelência operacional a mais importante e, para os entrevistados, a que tinha uma representação preponderante no mapa e na cultura da organização.

No início das suas operações, a empresa tinha uma vantagem comparativa suportada pelo uso do eucalipto como matéria-prima. Essa vantagem perdurou até que os concorrentes também passassem a utilizar a mesma matéria-prima, quando, então, a competitividade no setor passou a ser determinada por escalas de produção cada vez maiores e redução de custos. Até os anos 90 , não houve mudanças significativas nesse padrão de competição. O mercado para celulose de eucalipto era pulverizado, e a empresa contava com cerca de trezentos clientes orientados para o preço, a logística e a qualidade da polpa de celulose. Por outro lado, os clientes da empresa competiam entre si e diferenciavam seus produtos por meio da tecnologia que empregavam. Ou seja, a demanda para a empresa era sempre do mesmo tipo de produto, e a diferenciação ocorria mais à jusante na cadeia de valor do setor.

Entretanto, essa situação começou a se alterar no final dos anos 90, quando, por um lado, as empresas produtoras de papel consolidaram-se, passando a adquirir maiores volumes de celulose e tendo seu poder de barganha aumentado. Por outro lado, a empresa de celulose (objeto deste estudo) passou a firmar contratos com base em maiores volumes e de longo prazo (de três a sete anos), buscando garantir seu mercado e reduzir custos. Isso fez com que a competição nessa indústria passasse a ser realizada entre cadeias de valor e não mais entre empresas isoladas. 
Essa política trouxe consequências inesperadas para a empresa de celulose. Por um lado, os produtores de papel passaram a "depender" da empresa, pois não tinham alternativas no mercado para o volume de celulose que compravam. Por outro, o aumento da competição na ponta do consumo obrigou os produtores de papel a investirem em novos produtos que implicavam novos tipos de solicitações à empresa de celulose, tal como modificações na polpa de celulose que permitissem diferenciar seus produtos. A iniciativa emergente de diferenciação tomou corpo e, atualmente, há na empresa de celulose cinco linhas de produção que fabricam em torno de vinte e cinco diferentes tipos de celulose. Ou seja, toda a cadeia de valor foi conduzida em direção a uma estratégia de diferenciação e a relação passou a ser comandada pelos centros de pesquisa das empresas envolvidas, com intensa troca de informações técnicas e confidenciais.

\subsubsection{A combinação de estratégias deliberadas e emergentes e o papel da arquitetura organizacional na empresa de celulose}

Poucas foram as mudanças incorporadas na estrutura da empresa desde o surgimento da iniciativa emergente de diferenciação. Apesar de ser uma empresa industrial em que se espera uma interdependência sequencial natural ao seu processo produtivo, parecia que, pela distância de alguns departamentos da empresa, essa interdependência agrupada era mais praticada no nível da gestão. Isso porque, antes do surgimento da estratégia emergente, a demanda dos clientes entrava por meio de vários pontos na estrutura da empresa, como produção, centro de pesquisas e área comercial. Tais demandas subiam na hierarquia para serem encaminhadas, posteriormente, ao setor responsável. Essa prática criava, em geral, problemas de coordenação e demora na resposta ao cliente. Assim, a empresa passou a preocupar-se com funções de coordenação horizontal, nos níveis de contato com os clientes, que pudessem encaminhar as demandas recebidas.

Como decorrência, a área comercial criou a posição de account manager, responsável por ligar o cliente com as áreas de vendas, logística e técnica, sendo o elo para o atendimento das demandas e da resolução dos problemas. $\mathrm{O}$ centro de pesquisa passou a ter gerentes de produto e pesquisadores dedicados a determinados clientes, movimento necessário para preservar a confidencialidade das informações.

A empresa instituiu também um "Comitê de Satisfação", que tinha por objetivo encaminhar internamente as demandas dos clientes. Após o aparecimento da estratégia emergente e dos desafios de coordenação decorrentes, foi estabelecido um "Comitê DC/DO" formado pelos diretores e gerentes da diretoria comercial (DC) e de operações (DO) da empresa. Sua missão era encaminhar as questões de rotina que emergiam do conflito entre a diferenciação e a excelência operacional coexistentes na empresa. Entretanto, com o aumento das demandas dos clientes, essa alternativa de coordenação mostrou-se inviável.

Posteriormente, a empresa criou, em 2004, o "Comitê Processo-Produto" (CPP), composto por gerentes e coordenadores, representantes do Centro de Pesquisa e das áreas de Produção, Florestal, de Logística, de Suprimentos e Comercial. O comitê passou a compartilhar as decisões e a acomodar o conflito entre as estratégias de diferenciação e excelência operacional, convocando o comitê DC/DO em caso de impasses, em geral, comuns nas decisões que envolviam o aumento de custos. $\mathrm{O}$ CPP tinha liberdade, inclusive, para sugerir mudanças nos processos da empresa, que, contudo, deveriam ser ratificados pelos gerentes de interface e, eventualmente, pela diretoria. Embora as dificuldades relacionadas com o conflito de estratégias de diferenciação e excelência operacional tenham sido amenizadas com a criação do CPP, elas, entretanto, não desapareceram do ponto de vista dos gestores.

Outra melhoria implementada pela empresa se relacionava ao compartilhamento de informações. A informação, antes confinada a determinados departamentos, passou a ser gerenciada por um modelo de gestão do conhecimento. Ademais, alguns fóruns de compartilhamento de informações foram formalizados. Além disso, a empresa fez uso de muitos processos formalizados, tais como normas, procedimentos e instruções de trabalho, e, no 
nível gerencial, havia macroprocessos detalhados que estavam em funcionamento, embora ainda de maneira incipiente e informal, para alguns gestores.

O sistema de controle, baseado principalmente no orçamento, era todo dedicado à busca de excelência operacional e não mudou muito com o surgimento da estratégia emergente. Frequentemente, havia conflitos entre o que era demandado pelo cliente e o que residia no sistema de controle, visto que não existiam diretrizes que permitissem acomodar a diferenciação sob a estratégia de excelência operacional, como no caso de interrupção da produção para a realização de testes de novos produtos. Até hoje, essas situações são, vez ou outra, contornadas com uma autorização fornecida pela administração superior de desvio nos controles.

Por fim, o sistema de incentivo adotado para todos os colaboradores da empresa, denominado GPR, era estabelecido sobre indicadores de curto prazo com foco em: i) execução orçamentária; ii) gestão operacional; iii) melhoria contínua; iv) autocontrole. Para os entrevistados, tais indicadores reconheciam e reforçavam somente a excelência operacional, ou seja, o sistema centrava-se na redução dos custos. Assim, na visão deles, os sistemas de incentivo ainda precisavam ser alinhados à estratégia de diferenciação, o que, entretanto, só seria possível depois de solucionadas as questões de estrutura e parâmetros de controle.

Quadro 5 - Síntese evidências do caso B

\begin{tabular}{|c|c|}
\hline Categorias & Evidências \\
\hline Estratégia Deliberada & $\begin{array}{l}\text { - A estratégia inicial da empresa era o resultado mais da } \\
\text { visão dos principais executivos do que de análises } \\
\text { sistemáticas e racionais. } \\
\text { - A execução da estratégia era acompanhada por meio de } \\
\text { reuniões periódicas nas quais se comparava o que foi } \\
\text { realizado em relação ao previsto nos indicadores e no } \\
\text { orçamento. } \\
\text { - O mapa estratégico apresentava a excelência operacional } \\
\text { como a estratégia mais importante. }\end{array}$ \\
\hline Estratégia Emergente & $\begin{array}{l}\text { - A empresa passa a firmar contratos com base em } \\
\text { maiores volumes e de longo prazo (de três a sete anos). } \\
\text { - Essa política obrigou a empresa a criar cinco linhas de } \\
\text { produção que fabricam em torno de vinte e cinco } \\
\text { diferentes tipos de celulose. } \\
\text { - Toda a cadeia de valor foi conduzida em direção a uma } \\
\text { estratégia de diferenciação. } \\
\text { - A relação passou a ser comandada pelos centros de } \\
\text { pesquisa das empresas envolvidas, com intensa troca de } \\
\text { informações técnicas e confidenciais. }\end{array}$ \\
\hline
\end{tabular}

\begin{tabular}{|c|c|}
\hline $\begin{array}{c}\text { Combinação de } \\
\text { estratégias }\end{array}$ & $\begin{array}{l}\text { - Estratégia de excelência operacional (foco restrito) com } \\
\text { estratégia genérica de diferenciação que emerge de } \\
\text { pressões externas. }\end{array}$ \\
\hline $\begin{array}{c}\text { Fatores da arquitetura } \\
\text { organizacional }\end{array}$ & $\begin{array}{l}\text { - Com os problemas de coordenação e demora na resposta } \\
\text { ao cliente, a área comercial criou a posição de account } \\
\text { manager. } \\
\text { - O centro de pesquisa passou a ter gerentes de produto e } \\
\text { pesquisadores dedicados a determinados clientes. } \\
\text { - A empresa instituiu um "Comitê de Satisfação". } \\
\text { - Após o aparecimento da estratégia emergente, a empresa } \\
\text { estabeleceu um "Comitê DC/DO" formado pelos } \\
\text { diretores e gerentes da diretoria comercial (DC) e de } \\
\text { operações (DO) da empresa; } \\
\text { - A empresa criou, em 2004, o "Comitê Processo- } \\
\text { Produto" (CPP); } \\
\text { - A empresa implementou um compartilhamento de } \\
\text { informações com base em um modelo de gestão do } \\
\text { conhecimento. } \\
\text { - A empresa manteve o sistema de incentivo adotado para } \\
\text { todos os colaboradores, estabelecido sobre indicadores } \\
\text { de curto prazo. }\end{array}$ \\
\hline
\end{tabular}

Fonte: Dados da pesquisa.

\subsection{Discussão dos Casos}

Uma primeira leitura dos dados revela que ambas as empresas faziam uso do processo deliberado de formulação estratégica. A empresa de contact center optava por um processo baseado em análises racionais, conduzido por um grupo composto pelo presidente, diretores e gerentes, contando com o apoio de profissionais de suporte. Já na empresa de celulose, o processo de formulação estava centralizado na visão dos seus quatro diretores.

$\mathrm{Na}$ empresa de contact center, a principal diretriz, ou seja, de desenvolvimento de mercado - expansão no mercado com base em serviços desenvolvidos em seu principal cliente -, funcionava como uma estratégia "guarda-chuva", dando ao gestor razoável liberdade de ação. Essa autonomia parecia ser enfatizada pela estrutura descentralizada da empresa, pela pouca interdependência de tarefas e necessidade de coordenação entre unidades regionais e por um sistema de controle orientado pelo orçamento, mas, flexível, desde que alcançada a meta acordada com a empresa. A falta de um sistema de incentivo conectado aos indicadores de controle também parecia reforçar essa liberdade. Assim, a estratégia emergente de desenvolvimento de um novo serviço, no caso, a recuperação de créditos, surgiu dentro de seus limites, capitaneada por um gestor que percebeu uma 
nova oportunidade em seu ambiente e mobilizou recursos para aproveitá-la.

$\mathrm{Na}$ empresa de celulose, a orientação da estratégia deliberada tinha um escopo mais delimitado, ou seja, a busca da excelência operacional focada em ganhos de escala e padronização de operações. Para isso, utilizavase uma estrutura hierárquica muito especializada e com baixo grau de capacidade lateral. Sendo uma empresa industrial, na qual a interdependência sequencial seria o caminho natural, apresentava, em sua gestão, características de interdependência agrupada. Tinha uma hierarquia de orçamentos de curto prazo como principal meio de controle estratégico, conectado a um sistema de incentivos orientado para o curto prazo. Tudo isso parecia restringir iniciativas inovadoras internas. Portanto, a estratégia de diferenciação na empresa de celulose nasceu fora de seus limites, resultado do aumento de poder de barganha de clientes que impuseram suas condições sobre a empresa.

As duas empresas formalizaram as estratégias emergentes nos documentos que representavam a estratégia deliberada. Ou seja, reconheceram, retroativamente, a estratégia emergente. Porém, somente a empresa de contact center realizou a manipulação dos fatores de sua arquitetura organizacional para manter o comportamento estratégico nos níveis operacionais em linha com o conceito de estratégia corrente, acomodando o comportamento estratégico autônomo. A empresa trabalhou em sua estrutura e, ainda que parcialmente, na coordenação, nos processos organizacionais e nos sistemas de controle e incentivos, para acomodar a estratégia de "Recuperação de Créditos".

A Empresa de celulose não manipulou grande parte dos fatores da arquitetura organizacional dentro da qual a iniciativa emergente se formou. A estrutura, o sistema de controle e de incentivos não foram modificados para acomodar a estratégia emergente. A empresa conduziu ajustes em sua capacidade lateral por meio de diversas iniciativas, o que ajudou a diminuir as tensões decorrentes do conflito entre a estratégia deliberada e a estratégia emergente.

O Quadro 6 sintetiza e compara os principais atributos observados de cada um dos casos estudados:

\section{Quadro 6 - Caracterização das variáveis dos casos estudados}

\begin{tabular}{|l|l|l||}
\hline \multicolumn{1}{|c|}{ Categorias } & \multicolumn{1}{c|}{$\begin{array}{c}\text { CASO A } \\
\text { Contact Center }\end{array}$} & \multicolumn{1}{c||}{$\begin{array}{l}\text { CASO B } \\
\text { Celulose }\end{array}$} \\
\hline $\begin{array}{l}\text { Uso do processo } \\
\text { deliberado de } \\
\text { formulação } \\
\text { estratégica }\end{array}$ & \multicolumn{1}{|c||}{ Sim } & \multicolumn{1}{|c||}{ Sim } \\
\hline $\begin{array}{l}\text { Tipo e estratégia } \\
\text { deliberada na } \\
\text { época do } \\
\text { surgimento da } \\
\text { iniciativa } \\
\text { emergente }\end{array}$ & $\begin{array}{l}\text { Desenvolviment } \\
\text { o de Mercado } \\
\text { ("guarda- } \\
\text { chuva") }\end{array}$ & $\begin{array}{l}\text { "Excelência } \\
\text { operacional" } \\
\text { (foco restrito) }\end{array}$ \\
\hline $\begin{array}{l}\text { Estratégia } \\
\text { emergente }\end{array}$ & $\begin{array}{l}\text { Desenvolviment } \\
\text { o de Produto/ } \\
\text { Serviço }\end{array}$ & $\begin{array}{l}\text { Genérica: } \\
\text { "Diferenciação" }\end{array}$ \\
\hline $\begin{array}{l}\text { Característica do } \\
\text { surgimento da } \\
\text { iniciativa } \\
\text { emergente }\end{array}$ & $\begin{array}{l}\text { Fonte interna: } \\
\text { processo de } \\
\text { comprometiment } \\
\text { o de recursos } \\
\text { conduzido por } \\
\text { um gestor } \\
\text { autônomo }\end{array}$ & $\begin{array}{l}\text { Fonte externa: } \\
\text { natureza do } \\
\text { relacionamento } \\
\text { de troca com } \\
\text { clientes com } \\
\text { elevado poder de } \\
\text { barganha }\end{array}$ \\
\hline $\begin{array}{l}\text { Ajuste dos } \\
\text { fatores da } \\
\text { arquitetura } \\
\text { organizacional }\end{array}$ & $\begin{array}{l}\text { Parcial (somente } \\
\text { coordenação) }\end{array}$ \\
\hline Fonte: Elaborado
\end{tabular}

Fonte: Elaborado pelos autores.

\section{CONCLUSÕES}

Considerando o objetivo do artigo em investigar a dinâmica do surgimento de estratégias emergentes em organizações que fazem uso de processos deliberados de formulação estratégica, os resultados da pesquisa indicam que, em primeiro lugar, as empresas utilizam-se desse processo de combinação para aproveitar oportunidades de mercado que estão fora do escopo de sua estratégia deliberada. Tais oportunidades podem se tornar claras tanto a partir de uma consistência de decisões derivadas de fonte interna, como no caso da empresa de contact center, quanto a partir de uma consistência de decisões com motivação externa, como no caso da empresa de celulose. Dois aspectos parecem relevantes nessa discussão. Em primeiro lugar, as estratégias emergentes são fruto de percepções internas ou pressões externas e, em segundo, mudanças significativas na estratégia raramente se relacionam com um processo sistemático, mas, ao contrário, têm origem em um processo fragmentado, evolucionário e intuitivo. Esse resultado é consistente com as proposições de Araújo e Easton (1996), Quinn 
(1980) e Elbanna (2006).

Um segundo resultado parece indicar que a combinação de estratégias emergentes com estratégias deliberadas tem maiores possibilidades de ocorrer quando os planos deliberados possuem perspectivas amplas que permitem a emersão de iniciativas no seu interior (MINTZBERG; AHLSTRAND; LAMPEL, 2000; MARIOTTO, 2003). Há evidências, portanto, de que seja mais provável a mobilização de estratégias emergentes em empresas que fazem uso de processos formais de formulação estratégica com características mais amplas, ou seja, uma estratégia do tipo "guarda-chuva". Além disso, a perspectiva de uma estratégia formal mais ampla pode favorecer ainda mais a emersão de estratégias, se combinadas com uma arquitetura organizacional mais flexível (uma estrutura mais orgânica, sistemas de controle e incentivos mais flexíveis), como ilustrado no caso da empresa de contact center (DONALDSON, 1985; HREBINIAK, 2005; MINTZBERG; AHLSTRAND; LAMPEL, 2000; MARIOTTO, 2003). Por outro lado, há evidências de que o espaço para o surgimento e a consolidação de estratégias emergentes seja dificultado se o processo deliberado resultar em uma estratégia com foco mais estreito e, ao lado disso, uma estrutura hierárquica padronizada e especializada, bem como um sistema de controle mais rígido e incentivos de curto prazo (MINTZBERG; AHLSTRAND; LAMPEL, 2000).

Por fim, há indícios de que um aumento da capacidade lateral (GALBRAITH; DOWNEY; KATES, 2002) em organizações com estruturas mais mecânicas (DONALDSON, 1985) pode contribuir para minimizar as dificuldades e auxiliar no gerenciamento dos desafios colocados pelas estratégias emergentes. Entretanto, um conflito interno pode perdurar até que sejam ajustados os demais fatores da arquitetura organizacional (BUGELMAN, 1983a; GALBRAITH; DOWNEY; KATES, 2002), como ficou evidenciado no caso da empresa de celulose.

Uma primeira contribuição do estudo foi buscar um entendimento mais profundo do mecanismo de emersão de estratégias e da combinação delas com as estratégias deliberadas. $\mathrm{O}$ estudo evidenciou que tanto fatores internos como externos podem suscitar a emersão dessas estratégias. Além disso, a análise dos casos ainda sugere uma relação entre o escopo da estratégia deliberada e dos fatores da arquitetura organizacional como elementos facilitadores da emersão e da consolidação de estratégias emergentes. Isso significa que quanto mais restrito é esse escopo e quanto mais rígidos são os fatores da arquitetura organizacional maior é o grau de dificuldade para o surgimento e a consolidação de estratégias emergentes.

A segunda contribuição é a de que os resultados evidenciaram que fatores da arquitetura organizacional - estrutura, coordenação, sistemas de controle gerencial e de incentivos - contribuem tanto para o aparecimento das estratégias emergentes como para a sua consolidação nas organizações. Ao se evidenciar como tais fatores agem, uma contribuição desta pesquisa - para além do avanço da literatura - foi demonstrar como esses fatores da arquitetura, mormente a habilidade da organização na construção de mecanismos de coordenação lateral, são fundamentais nesse processo.

A despeito dos resultados, algumas limitações devem ser consideradas no presente estudo. Uma delas é relativa ao número pequeno de casos. Um maior número de casos permitiria maior robustez na análise e na identificação e compreensão mais acurada de padrões entre casos (EISENHARDT, 1989). Todavia, o tema da estratégia ainda suscita relutância por parte das empresas em permitir acesso aos dados para pesquisa, o que não permitiu uma pesquisa mais ampla com maior número de casos.

Outra limitação está relacionada com os momentos distintos de ciclo de vida organizacional vividos pelas duas empresas objeto do estudo, com efeitos sobre a comparabilidade dos casos e das análises efetuadas. A empresa de contact center, jovem e aberta a tudo que representasse oportunidade de crescimento, parecia estar em um momento mais propício para acolher iniciativas inovadoras, ao contrário da empresa de celulose, mais madura, e com um modelo de organização mais sedimentado.

Finalmente, a partir dos resultados do estudo, acredita-se que algumas linhas de pesquisa podem dar continuidade e 
aprofundamento aos achados nesta investigação. Assim, sugerem-se como tópicos para futuras pesquisas: i) entender a importância do grau de centralização da decisão no estabelecimento de um processo de empreendimento corporativo interno, isto é, de emersão de estratégias; ii) Aprofundar os estudos a respeito de como as empresas podem estabelecer uma arquitetura organizacional reconfigurável com o objetivo de fomentar estratégias emergentes; iii) compreender com mais profundidade se arquiteturas organizacionais mais flexíveis são mais apropriadas para o surgimento e a consolidação de estratégias emergentes.

\section{REFERÊNCIAS}

AMIN, Saman Hassanzadeh; RAZMI, Jafar; ZHANG, Guoqing. Supplier selection and order allocation based on fuzzy SWOT analysis and fuzzy linear programming. Expert Systems with Applications, v. 38, n. 1, p. 334 342,2011

ANDERSEN, Torben Juul. Integrating The Strategy Formation Process: An International Perspective. European Management Journal, v. 22, n. 3, p. 263272,2004

ANDREWS, K. The concept of corporate strategy. Homewood: Richard Irwin, 1980.

ANTHONY, R.; GOVINDARAJAN, V. Management control systems. New York: McGraw-Hill, 2000.

ARAÚJO, L; EASTON, G. Strategy: where is the pattern? Organization, v. 3, n. 3, p.361-383, Aug. 1996.

BIGNETTI, Luiz Paulo; PAIVA, Ely Laureano. Ora (direis) ouvir estrelas!: estudo das citações de autores de estratégia na produção acadêmica brasileira. Revista de Administração Contemporânea, v. 6, n. 1, p. 105-125, 2002

BONOMA, Thomas V. Case research in marketing: opportunities, problems, and a process. Journal of Marketing Research, v. 22, n. 2, p. 199-208, 1985.

BOSSIDY, L; CHARAN, R. Desafio: fazer acontecer. Rio de Janeiro: Elsevier, 2003.

BURGELMAN, R. A. A model of the interaction of strategic behavior, corporate context, and the concept of strategy. Academy of Management Review, v. 8, n.1, p.61-70. 1983a.

BURGELMAN, R. A. A process model of the interaction corporate venturing in the diversified major firm. Administrative Science Quarterly, v. 28, p. 223-244, 1983b.

BURNS, T; STALKER, G. M. The management of innovation. London: Tavistock, 1961.

CALDEIRA, Adilson; LEX, Sergio; MORAES, Cláudio Alberto de; TOLEDO, Luciano Augusto. Estratégias emergentes e deliberadas: o processo de formação de estratégias sob o prisma do método do estudo de caso. Sistemas \& Gestão, v. 4, n. 3, p. 221-237, 2009.

CHANDLER, A. Introduction a strategy and structure. In: McGRAW, Thomas K. (Org.). Alfred Chandler: ensaios para uma teoria histórica da grande empresa. Rio de Janeiro: FGV, 1998.

DONALDSON, L. Organization design and the lifecycles of products. Journal of Management Studies, v. 22 , n. 1, p. $25-37,1985$.

DYSON, Robert G. Strategic development and SWOT analysis at the University of Warwick. European Journal of Operational Research, v. 152, n. 3, p. 631-640, 2004.

EISENHARDT, K. Building theories from case study research. Academy of Management Review, v.14, n.4, p.532-550, 1989.

ELBANNA, Said. Strategic decision-making: Process perspectives. International Journal of Management Reviews, v. 8, n. 1, p. 1-20, 2006.

GALBRAITH, Jay R. Designing organizations: an executive guide to strategy, structure, and process. San Francisco: Jossey-Bass, 2002.

GALBRAITH, Jay; DOWNEY, Diane; KATES, Amy. Designing dynamic organizations: a hand-on guide for leaders at all levels. New York: Amacon, 2002.

GASKELL, George. Entrevistas individuais e grupais. In: BAUER, Martin W.; GASKELL, George. Pesquisa Qualitativa com Texto, Imagem e Som: um manual prático. 2. ed. Petrópolis: Vozes, 2003, p. 65-83.

GHOSHAL, S.; GRATTON, L. Integrating the enterprise. Sloan Management Review, v. 44, n. 1, p. 31-38, 2002.

GILMORE, F. F; BRANDENBURG, R. G. Anatomy of corporate planning. Harvard Business Review, v. 40, n. 
6, p. 61-69, 1962.

GOLDEN, Brian R. The past is the past - or is it? The use of retrospective accounts as indicators of past strategy. Academy of Management Journal, v. 35, n. 4, p. 848$860,1992$.

HAGE, J. An axiomatic theory of organizations. Administrative Science Quarterly, v. 10, n. 3, p. 289320. 1965.

HAMBRICK, D. C; CANNELLA, A. A. Strategy implementation as substance and selling. Academy of Management Executive, v. 3, n. 4, p. 278-285.1989.

HAX, A.; MAILUF, N. The strategy concept \& process. New Jersey: Prentice-Hall, 1991.

HAYES, R. H; JAIKUMAR, R. Manufacturing's crisis: new technologies, obsolete organizations. Harvard Business Review, v. 5, p. 77-85, 1988.

HREBINIAK, L. G. Making strategy work. New Jersey: Wharton School Publishing, 2005.

HUNGER, J. D.; WHEELEN, T. L. Gestão estratégica: princípios e prática. Rio de Janeiro: Reichmann e Affonso Editores, 2002.

JARZABKOWSKI, Paula; SHAW, Duncan. Shaping strategic action through the rhetorical construction and exploitation of ambiguity. Organization Science, v. 23, n. 3, p. 630-650, 2012.

JICK, T. Mixing qualitative and quantitative methods: triangulation in action. Administrative Science Quarterly, v. 24, n. 4, p. 602-611, 1979.

JOHNSON, G. Strategic change and the management process. New York: Basil Blackwell, 1987.

KARGER, Delmar W.; MALIK, Zafar A. Long range planning and organizational performance. Long Range Planning, v. 8, n. 6, p. 60-64, 1975.

KUKALIS, S. Determinants of strategic planning systems in large organizations: a contingency approach. Journal of Management Studies, v. 28, n. 2, p. 143-160, 1991.

LAVARDA, Rosalia Aldraci Barbosa; CANET-GINER, María Teresa; PERIS-BONET, Fernando Juan. How Middle Managers Contribute to Strategy Formation Process: Connection of Strategy Processes and Strategy Practices. Revista de Administração de Empresas, São Paulo, v. 50, n. 4, 2010.
LAVARDA, Rosalia Aldraci Barbosa; CANETGINER, María Teresa; PERIS-BONET, Fernando Juan. Understanding how the strategy formation process interacts with the management of complex work. European Business Review, v. 23 n. 1, p. 71-86, 2011.

LEONTIADES, M; TEZEL, A. Planning perceptions and planning results. Strategic Management Journal, v.1, n.1, p. $65-76,1980$.

LINDBLOM, C. The science of muddling through. Public Administration Review, v. 19, n. 2, p. 79-88, 1959.

LORANGE, P; VANCIL, R. F. Strategic planning systems. New Jersey: Prentice Hall, 1977.

MARIOTTO, F. L. Mobilizando estratégias emergentes. Revista de Administração de Empresas, v. 43, n. 2, p. 78-93, 2003.

MANTERE, Saku. Role expectations and middle manager strategic agency. Journal of Management Studies, v. 45, n. 2, p. 294-316, 2008.

MAYO, M; BROWN, G. Building a competitive business model. Ivey Business Journal, v. 63, n. 3, p. 18-23, 1999.

MILlES, Mathew B.; HUBERMAN, A. Michael. Qualitative data analysis. 2.ed. USA: Sage Publication, 1994.

MINTZBERG, H. Ascensão e queda do planejamento estratégico. Porto Alegre: Bookman, 2004.

MINTZBERG, H. Patterns in strategy formation. Management Science, v. 24, n. 9, p. 934-948, 1978.

MINTZBERG, H.; AHLSTRAND, B; LAMPEL, J. Safári de estratégia: um roteiro pela selva do planejamento estratégico. Porto Alegre: Bookman, 2000.

MINTZBERG, H.; QUINN, J. B.; GHOSHAL, S. O processo da estratégia: conceitos, contextos e casos selecionados. 4. ed. Porto Alegre: Bookman, 2006.

OLIVEIRA, Murilo Alvarenga; SAUAIA, Antonio Carlos Aidar; MOTTA, Gustavo da Silva; GARCIA, Pauli Adriano de Almada. Combinando Estratégias Deliberadas e Emergentes: um Estudo com jogos de Empresa. In: V 3Es - Encontro de Estudos em Estratégia - ANPAD, Porto Alegre, 2011.

PEARCE, J. A.; ROBBINS, D. K.; ROBINSON, R. B. The impact of grand strategy and planning formality on 
financial performance. Strategic Management Journal, v. 8 , n. 2, p. $125-134,1987$.

QUINN, J. Logical incrementalism. In: WIT, B.; MEYER, R. Strategy: process, content, context. London: International Thomson Business Press, p. 173-184, 1980.

RAPS, A. Implementing strategy. Strategic Finance, v.85, n.12, p. 49-53, 2004.

RIGBY, D. K. How to manage the management tools. Planning Review, v. 22, n. 5, p. 8-15, 1993.

ROBINSON, R. B; PEARCE, J. A. The impact of formalized planning on financial performance in small organizations. Strategic Management Journal, v. 4, n. 3, p. 197-208, 1983.

SAPP, R. W; SEILER, R. E. The relationship between long range planning and financial performance of U.S. commercial banks. Managerial Planning, v. 30, n. 2, p. 32-36, 1981.

SAUTER, Vicki L. Intuitive decision-making. Communications of the ACM, v. 42, n. 6, p. 109-115, 1999.

SILLINCE, John; JARZABKOWSKI, Paula; FENTON, Evelyn. Strategizing and organizing in pluralistic contexts. Long Range Planning, v. 39, n. 6, p. 631-648, 2006.

STEINER, G. A. Top management planning. New York: Macmillan, 1969.

STEINER, G. A. Strategic planning: what every manager must know. New York: Free Press, 1979.

STONICH, Paul J. Using rewards in implementing strategy. Strategic Management Journal, v. 2, n. 4, p. 345-352, 1981.

THUNE, S. S; HOUSE, R. J. Where long range planning pays off. Business Horizons, v. 13, n. 4, p. 81-87, 1970.

WOODWARD, J. Industrial organization: theory and practice. London: Oxford University Press, 1965.

YIN, Robert K. Estudo de caso: planejamento e métodos. Porto Alegre: Bookman, 2005. 